\title{
Abstracts
}

Articles appearing in the August 2018 issue

Expanding the phenotype of de novo SLC25A4-linked mitochondrial disease to include mild myopathy

Objective To determine the disease relevance of a novel de novo dominant variant in the SLC25A4 gene, encoding the muscle mitochondrial adenosine diphosphate (ADP)/adenosine triphosphate (ATP) carrier, identified in a child presenting with a previously unreported phenotype of mild childhood-onset myopathy.

Methods Immunohistochemical and Western blot analysis of the patient's muscle tissue were used to assay for evidence of mitochondrial myopathy and for complex I-V protein levels. To determine the effect of a putative pathogenic p.Lys33Gln variant on ADP/ATP transport, the mutant protein was expressed in Lactococcus lactis and its transport activity was assessed with fused membrane vesicles.

Results Our data demonstrate that the heterozygous c.97A $>$ T (p.Lys33Gln) SLC25A4 variant is associated with classic muscle biopsy findings of mitochondrial myopathy (cytochrome $\mathrm{C}$ oxidase-deficient and ragged blue fibers), significantly impaired ADP/ATP transport in L lactis, and decreased complex I, III, and IV protein levels in patient skeletal muscle. Nonetheless, the expression levels of the total ADP/ATP carrier (AAC) content in the muscle biopsy were largely unaffected.

Conclusions This report further expands the clinical phenotype of de novo dominant SLC25A4 mutations to a childhood-onset, mild skeletal myopathy, without evidence of previously reported clinical features associated with SLC25A4-associated disease, such as cardiomyopathy, encephalopathy, or ophthalmoplegia. The most likely reason for the milder disease phenotype is that the overall AAC expression levels were not affected, meaning that expression of the wild-type allele and other isoforms may in part have compensated for the impaired mutant variant.

NPub.org/NG/9112a

\section{SCN11A Arg225Cys mutation causes nociceptive pain without detectable peripheral nerve pathology}

Objective The SCN11A gene encodes the $\mathrm{Na}_{V} 1.9$ sodium channel found exclusively in peripheral nociceptive neurons.

Methods All enrolled participants were evaluated clinically by electrophysiologic studies, DNA sequencing, and punch skin biopsies.

Results All affected family members have episodes of pain. Pain was predominantly nociceptive, but not neuropathic in nature, which led to a diagnosis of fibromyalgia in some patients. All patients had normal findings in nerve conduction studies for detecting large nerve fiber neuropathies and skin biopsies for detecting small nerve fiber pathology.

Conclusions Unlike those patients with missense mutations in SCN11A, small fiber sensory neuropathy, and neuropathic pain, the Arg225Cys SCN11A in the present study causes predominantly nociceptive pain with minimal features of neuropathic pain and undetectable pathophysiologic changes of peripheral neuropathy. This finding is consistent with dysfunction of nociceptive neurons. In addition, since nociceptive pain in patients has led to the diagnosis of fibromyalgia, this justifies a future search of mutations of SCN11A in patients with additional pain phenotypes such as fibromyalgia to expand the clinical spectrum beyond painful small fiber sensory neuropathy.

NPub.org/NG/9112b

B
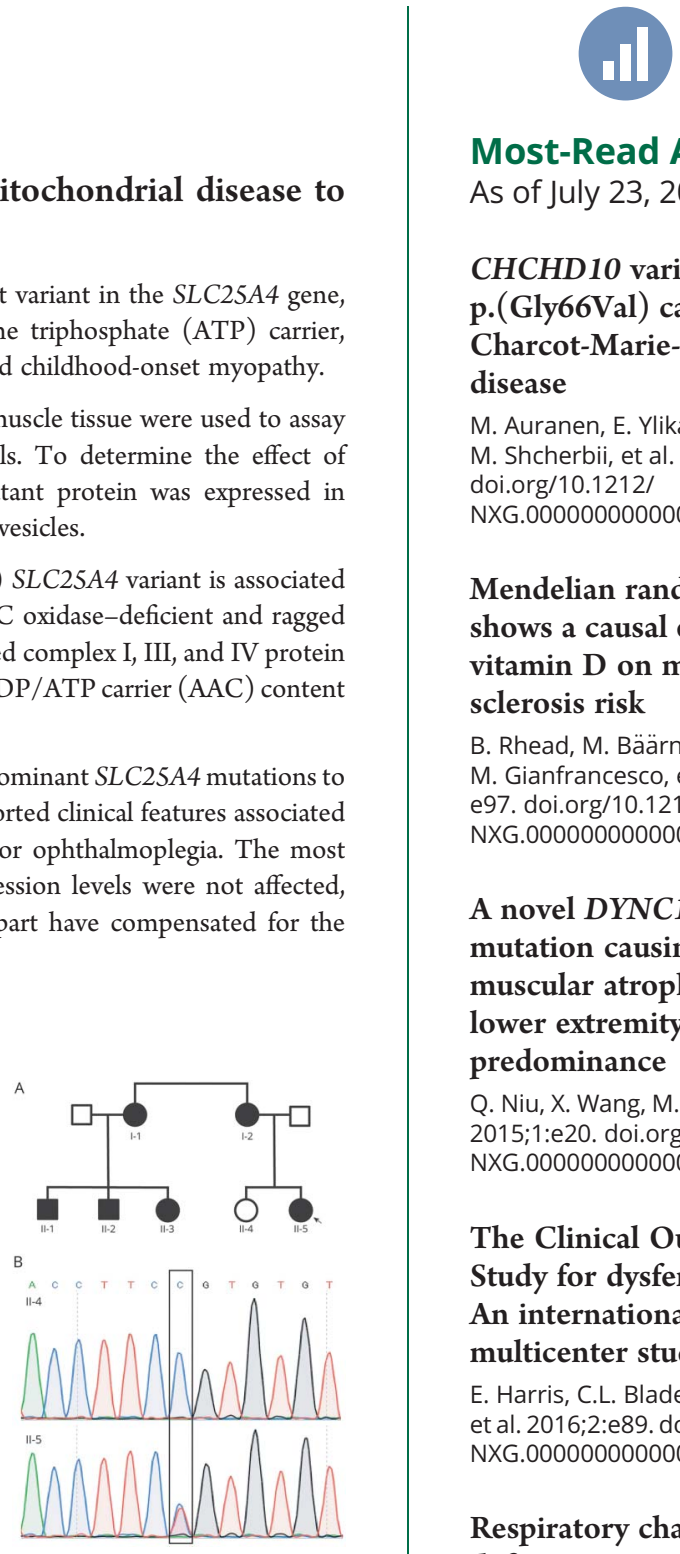

Most-Read Articles

As of July 23, 2018

CHCHD10 variant

p.(Gly66Val) causes axonal

Charcot-Marie-Tooth

disease

M. Auranen, E. Ylikallio,

M. Shcherbii, et al. 2015;1:e1.

doi.org/10.1212/

NXG.0000000000000003

Mendelian randomization shows a causal effect of low vitamin $\mathrm{D}$ on multiple sclerosis risk

B. Rhead, M. Bäärnhielm, M. Gianfrancesco, et al. 2016;2: e97. doi.org/10.1212/

NXG.0000000000000097

\section{A novel DYNC1H1} mutation causing spinal muscular atrophy with lower extremity predominance

Q. Niu, X. Wang, M. Shi, and Q. Jin. 2015;1:e20. doi.org/10.1212/ NXG.0000000000000017

\section{The Clinical Outcome} Study for dysferlinopathy: An international multicenter study

E. Harris, C.L. Bladen, A. Mayhew, et al. 2016;2:e89. doi.org/10.1212/ NXG.0000000000000089

Respiratory chain deficiency in nonmitochondrial disease

A. Pyle, H.J. Nightingale, H. Griffin, et al. 2015;1:e6. doi.org/10.1212/ NXG.0000000000000006 


\title{
Neurology
}

\author{
What's happening in Neurology ${ }^{\circledR}$ Genetics \\ Neurology 2018;91;557 \\ DOI 10.1212/WNL.0000000000006301
}

This information is current as of September 17, 2018

\section{Updated Information \&} Services

Permissions \& Licensing

\section{Reprints}

including high resolution figures, can be found at: http://n.neurology.org/content/91/12/557.full

Information about reproducing this article in parts (figures,tables) or in its entirety can be found online at:

http://www.neurology.org/about/about_the_journal\#permissions

Information about ordering reprints can be found online:

http://n.neurology.org/subscribers/advertise

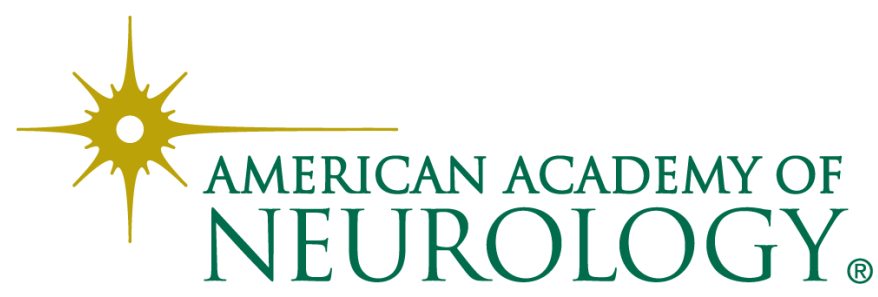

